\title{
Assessment of Tidal Current Power Potency in Kelabat Bay, Indonesia
}

\author{
Harman Ajiwibowo ${ }^{\# 1}$, Munawir B. Pratama ${ }^{\# 2}$, Andojo Wurjanto ${ }^{\# 3}$ \\ \#Faculty of Civil and Environmental Engineering, Bandung Institute of Technology \\ Jalan Ganesha 10, Bandung 40132, Indonesia \\ ${ }^{1}$ harman.ajiwibowo17@gmail.com \\ 2 munawirbintang@gmail.com \\ 3 andojowurjanto@ocean.itb.ac.id
}

\begin{abstract}
Indonesian energy production is dominated by non-renewable sources. To promote exploration of more sustainable energy sources, the current study focuses on determination of energy from tidal-current-induced power. The study includes field measurement, numerical modeling using MIKE3 (personal license), tidal model analysis, and power calculation. The field measurements include bathymetric, tidal, and current velocity surveys using an Argonaut-XR type Acoustic Current Doppler Profiler. The narrowest part of the bay is selected as the area of interest. Validation of the water elevation and current numerical model results with field measurements shows good agreement, with average errors of $5.34 \%$ for water elevation validation and $8.8 \%$ for tidal current validation. The model shows that the eastern part of the area of interest has the highest tidal-current velocity magnitude. The average and peak velocity magnitudes are 0.373 and $1.24 \mathrm{~m} / \mathrm{s}$, respectively. A Gorlov helical turbine is selected as the turbine for energy harvesting, because it has suitable height and cut-in-speed characteristics. Although the calculated generated power can only supply half of the average Indonesian consumption per capita, it is hoped that this study will provide an initial step toward sustainable power harvesting in Indonesia.
\end{abstract}

Keyword - Numerical modeling, Ocean renewable energy, Tidal current, Kelabat Bay, Indonesia

\section{INTRODUCTION}

Global climate changes have been seen worldwide lately, mainly caused by mass production of nonsustainable energy in most nations including Indonesia. During 2014, the share of non-renewable energy production in Indonesia was six times higher [1] than the share of renewable production. To overcome the negative effects of climate change, the development of infrastructure for harvesting renewable energy is deemed important. The issue is how to harvest the energy as efficiently as possible. Ocean-based renewable energy should receive the foremost attention since it has abundant potential.

Previous studies show that tidal current is one of the most reliable forms of potential ocean-based energy sources among ocean thermal and wave energy sources. The technology is more accessible and well-established. Studies of tidal current power extraction have been well-developed in the past few years across the globe, for example in Scotland [2], India [3], Japan [4], Canada [5], and several others [6].

The potency of tidal current in Kelabat Bay (Province of Kepulauan Bangka Belitung of Indonesia) will be assessed. The scope of this study covers several areas such as field measurement, numerical modeling, tidal model analysis, turbine selection, and power calculation.

\section{STUDY LOCATION}

Kelabat Bay is located at the northern part of Bangka Island, as shown in Fig. 1. Kelabat Bay is located in the range of 565,000-591,000 mE and 9,799,000-9,832,000 mS at region 48 south of UTM coordinate. Kelabat Bay links the districts of Jebus and Kelapa of West Bangka Regency and the districts of Belinyu and Riau Silip of Bangka Regency. Therefore, local small ship navigation is rather dense. Fishing boats, passenger ships, and tin dredger vessels pass through the bay frequently.

The tidal characteristic in Kelabat Bay is found to be of diurnal type with a tidal range of $1.7 \mathrm{~m}$, while the maximum current velocity in Kelabat Bay is expected to be around 1.5 knots [8].

Kelabat Bay is divided into three regions: the inner, narrowest, and outer regions (see Fig. 1b.) The average depths in the outer and inner regions are 8 and $5 \mathrm{~m}$, respectively [8]. Meanwhile the narrowest area is deeper, with an average depth of over $10 \mathrm{~m}$. The bay is approximately 13, 1.7, and $10.7 \mathrm{~km}$ wide in the outer, narrowest, and inner regions, respectively. It is expected that the combination of tidal propagation and the geometrical shape of the bay will cause high current velocity, especially in the narrowest part. The planned location for power harvesting is the narrowest part, as demarcated in Fig. 1b by a red box. 

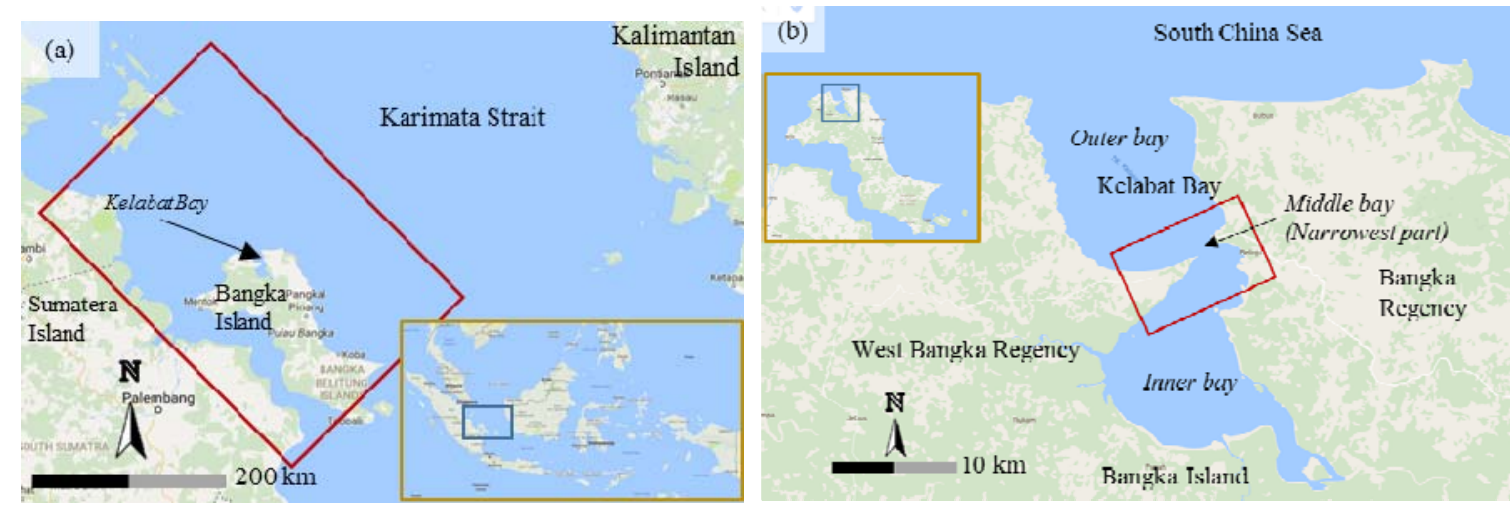

Fig. 1. Locations of (a) Bangka Island and (b) Kelabat Bay

\section{III.FIELD MEASUREMENT}

Three types of field measurements were carried out, namely bathymetric, tidal, and current velocity surveys. The locations of the tidal and current velocity surveys were in the narrowest part of the bay, namely at points S1 and S2, respectively. They can be seen in Fig. 2.
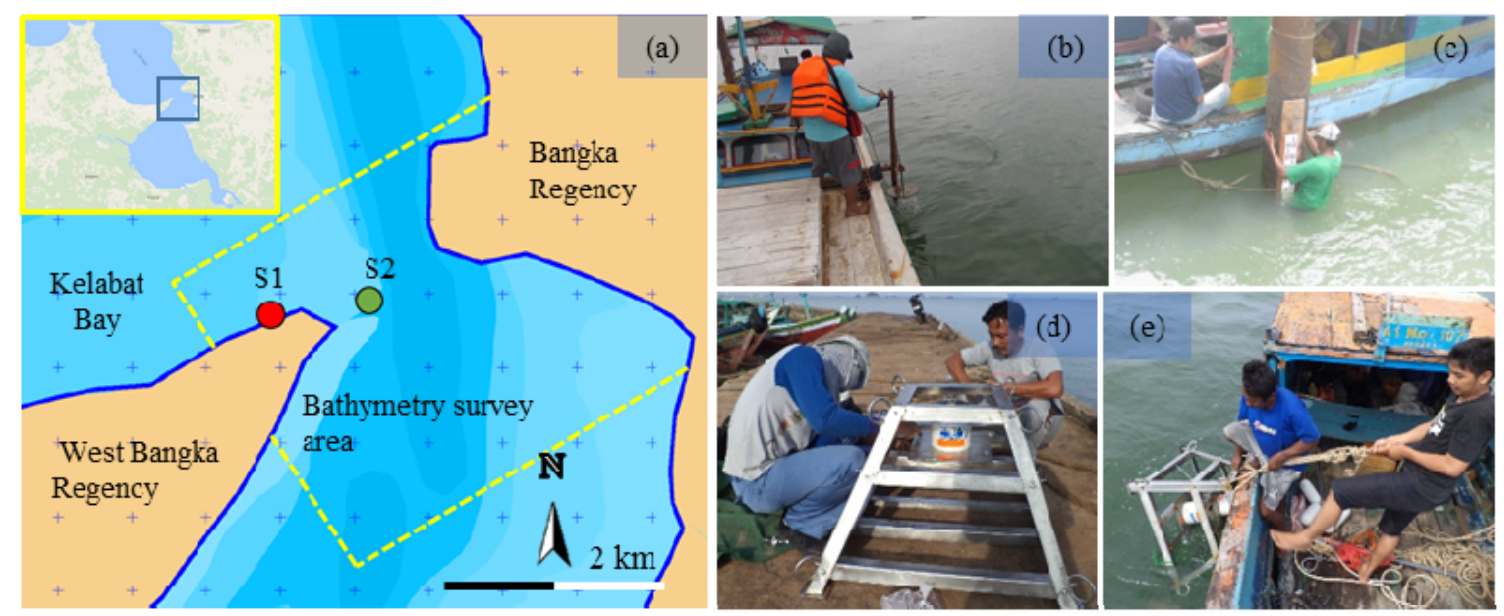

Fig. 2. (a) Location and (b-e) documentation of field measurement activities

\section{A. Bathymetry}

A bathymetric chart is needed as the base map for modeling. The equipment used was a GPS Single Beam Echosounder. The area covered by the bathymetric survey can be seen in Fig. 2a. The water depth in the middle of the narrowest part is around $20 \mathrm{~m}$. Meanwhile the depth of the inlet to the bay from the South China Sea is around $20 \mathrm{~m}$ as well.

\section{B. Surface Elevation}

Tidal elevation is observed hourly on the peilschaal installed in a nearby local jetty (see Fig. 2c). The location is shown in Fig. 2a as point S1. The location of S1 is a calm area. The surface elevation is recorded hourly for 15 days (half-moon cycle) from December 21, 2013 to January 4, 2014. The survey shows that the tidal range is $2.1 \mathrm{~m}$ and the tidal characteristic in Kelabat Bay is the diurnal type.

\section{Tidal Current}

The location of the tidal current velocity measurement is denoted by point S2 (see Fig. 2a). The current velocity is measured using an Acoustic Current Doppler Profiler (ADCP), Argonaut-XR with a 0.75-Mhz autonomous multi-cell system specification. Figs. 2d and 2c show the activity of the ADCP arrangement and deployment. The location of the tidal current velocity survey is denoted by point S2, as seen in Fig. 2a. The ADCP is positioned at a height of $0.8 \mathrm{~m}$ above the seabed and consists of 10 layers of current measurement in all directions. Layer 1 is above the ADCP and the blank area (the blank area is about $70 \mathrm{~cm}$ in height), and layer 10 is located at the top underneath the surface of the water. Fig. 3 illustrates the ADCP and its layers of measurement. 
The measured tidal current velocity at S2 varies in all cells, with the average velocity ranging from 23.4 to $35.8 \mathrm{~cm} / \mathrm{s}$, the minimum velocity from around 0.1 to $1.3 \mathrm{~cm} / \mathrm{s}$, and the maximum velocity from 71.5 to 102.4 $\mathrm{cm} / \mathrm{s}$. The lowest and highest tidal current velocities are recorded in layers 1 and 10 . The direction of the tidal current velocity is also known to be predominantly oriented from northwest to southeast when transitioning from flood to ebb. Meanwhile, the opposite is the case during the transition from ebb to flood.

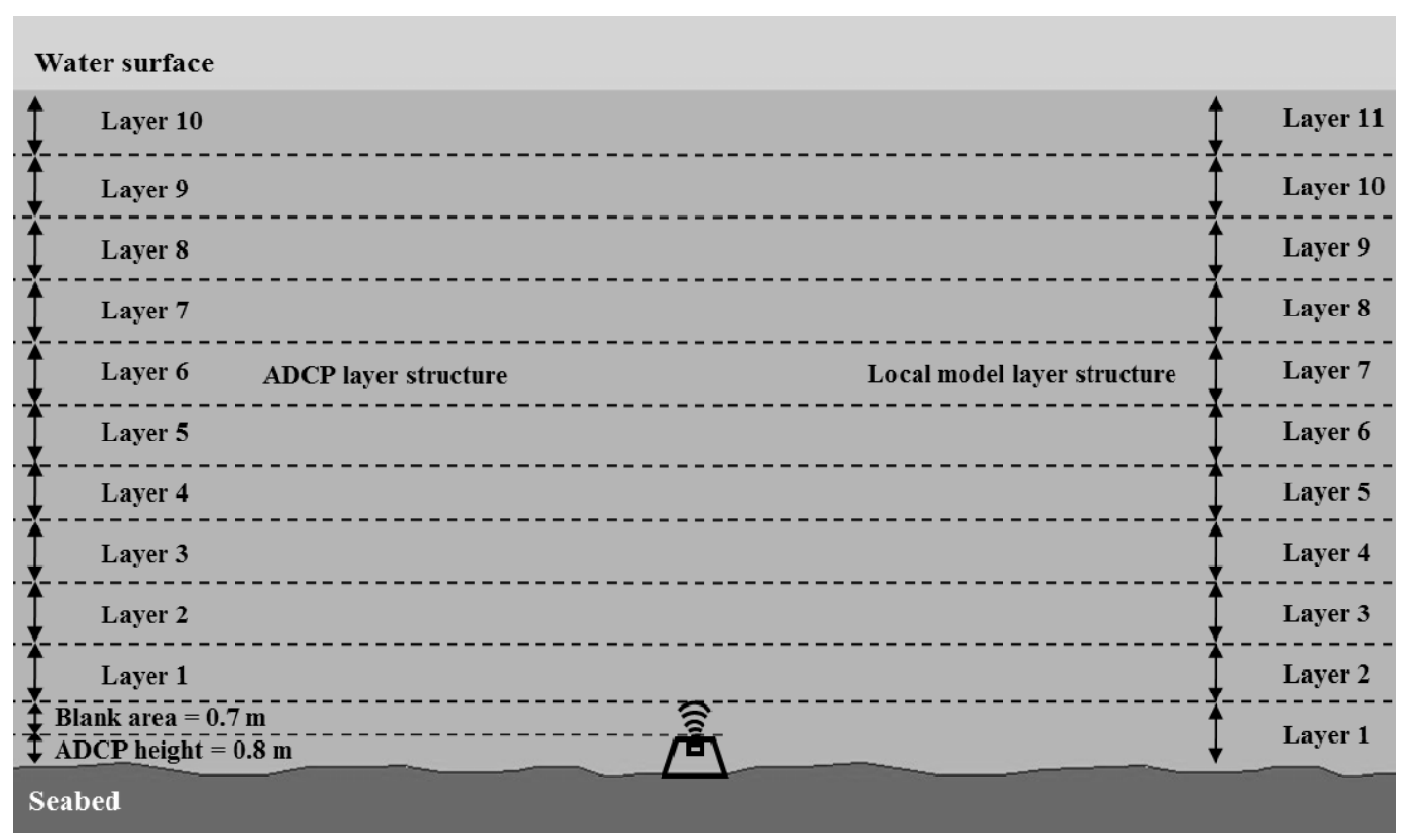

Fig. 3. Layer structure of ADCP

\section{IV.NUMERICAL MODEL}

Numerical modeling is conducted to simulate a time series of the 3-D current velocity distribution in Kelabat Bay. The model is also used in simulating flood [9], coastal, estuary, and river processes [10], and environmental control [11].

In this study, MIKE3 (personal license) is used to determine the velocity distribution to select locations of higher magnitude of continuous velocity. Other similar studies at different locations use models such as Delft3D [3], Telemac [2], ROMS (Regional Ocean Modeling System) [12], FVCOM (Finite Volume Coastal Ocean Model) [13], and MIKE [6].

\section{A. Governing Equations}

MIKE3 is a finite-element-based tool. A 3-D hydrodynamic model with sigma coordinates is developed using MIKE3. The model solves the 3-D incompressible Reynolds averaged Navier Stokes (RANS) equations, using the Boussinesq and hydrostatic pressure assumptions [14].

Equation (1) shows the local continuity equation for the model, which is performed in Cartesian and sigma coordinates, while the two horizontal momentum equations for the $\mathrm{x}$ - and $\mathrm{y}$ - components are given by Eqs. (2) and (3).

$$
\begin{aligned}
& \frac{\partial h}{\partial t}+\frac{\partial h u}{\partial x^{\prime}}+\frac{\partial h v}{\partial y^{\prime}}+\frac{\partial h \omega}{\partial \sigma}=h S \\
& \frac{\partial h u}{\partial t}+\frac{\partial h u^{2}}{\partial x^{\prime}}+\frac{\partial h v u}{\partial y^{\prime}}+\frac{\partial h \omega u}{\partial \sigma}=f v h-g h \frac{\partial \eta}{\partial x^{\prime}}-\frac{h}{\rho_{0}} \frac{\partial p_{a}}{\partial x^{\prime}}-\frac{h g}{\rho_{0}} \int_{z}^{n} \frac{\partial \rho}{\partial x} d z-\frac{1}{\rho_{o}}\left(\frac{\partial s_{x x}}{\partial x}+\frac{\partial s_{x y}}{\partial y}\right) \\
& +h F_{u}+\frac{\partial}{\partial \sigma}\left(\frac{v_{v}}{h} \frac{\partial u}{\partial \sigma}\right)+h u_{s} S \\
& \frac{\partial h v}{\partial t}+\frac{\partial h u v}{\partial x^{\prime}}+\frac{\partial h v^{2}}{\partial y^{\prime}}+\frac{\partial h \omega v}{\partial \sigma}=-f u h-g h \frac{\partial \eta}{\partial y^{\prime}}-\frac{h}{\rho_{0}} \frac{\partial p_{a}}{\partial y^{\prime}}-\frac{h g}{\rho_{0}} \int_{z}^{n} \frac{\partial \rho}{\partial y} d z-\frac{1}{\rho_{o}}\left(\frac{\partial s_{y x}}{\partial x}+\frac{\partial s_{y y}}{\partial y}\right) \\
& +h F_{v}+\frac{\partial}{\partial \sigma}\left(\frac{v_{v}}{h} \frac{\partial v}{\partial \sigma}\right)+h v_{s} S
\end{aligned}
$$


where $t$ is the time; $x^{\prime}, y^{\prime}$, and $\sigma$ are the modified Cartesian co-ordinates; $u, v$, and $\omega$ are the velocities in the $x, y$, and $z$ directions; $h$ is the total water depth; $\eta$ is the difference from water level to the mean sea level (MSL); $f$ is the Coriolis parameter; $g$ is the gravitational acceleration; $p_{a}$ is the atmospheric pressure; $\rho_{o}$ is the fluid density; $v_{s}$ is the vertical turbulent viscosity; $s_{x x}, s_{x y}, s_{y x}$, and $s_{y y}$ are the radiation stress components; and $S$ is the magnitude of the point sources discharge, with $u_{s}$ and $v_{s}$ as the velocity of the discharge.

\section{B. Model Setup}

Numerical modeling is carried out in two stages: regional and local modeling, where both models are executed in Cartesian and sigma coordinates. The global model covers Bangka Strait and Karimata Strait, as shown in Figs. 4a and 1a (red box). This model aims to produce a valid surface elevation model in the domain. Obtaining a valid tidal current velocity model requires a more detailed mesh resolution. In order to optimize the computational time, a valid and detailed current velocity model is developed as a local model that only covers the middle of Kelabat Bay, as shown in Figs. $4 \mathrm{~b}$ and $1 \mathrm{~b}$ (red box).

The model applies to both offline and online nesting. Offline nesting is performed in the transition from global to local model. Henceforth the result of the global model is used to derive the water-level boundary condition of the local model. The online nesting is shown with the mesh becoming finer in the area of interest in both models.

The maximum and minimum mesh resolutions of the global model are $2.5 \mathrm{~km}$ and $500 \mathrm{~m}$, respectively. Moving from the boundary at Karimata Strait and Bangka Strait into the bay, the grid becomes finer. The resulting base map from the bathymetric survey combined with a navigational chart map from the Indonesian navy was used. The open web application NaoTide was used to develop the tidal fluctuation as the boundary condition at the outer boundary of the global model.

Meanwhile, in the local model, the maximum and minimum mesh resolutions are $1.1 \mathrm{~km}$ and $60 \mathrm{~m}$. The local model was run to provide a detailed model of the tidal current velocity in Kelabat Bay, which resulted in 11 layers of tidally induced current velocity. The 11 layers mentioned above are one blank spot layer covering the height of the ADCP and a distance of $80 \mathrm{~cm}$ above the ADCP and 10 layers of current velocity. This conforms to the ADCP 10 measurement cell.

\section{Model Validation}

Model validation is carried out by comparing the model output with the current velocity obtained from field measurements. Notably in hydrodynamic modeling, the two most common parameters for validation are the surface elevation and current velocity [4]. The errors are calculated with a simple formula as shown in Eq. (4), where $\eta_{\text {Numerical Model }}$ is the result of the numerical model and $\eta_{\text {Field Measurement }}$ is the value of the field measurement data.

Error $=\frac{\mid \text { Numerical Model ResultValue }- \text { Field Measurement DataValue } \mid}{\text { Field Measurement MaximumValue }}$

1) Surface Elevation Validation: The surface elevation model used for the global model is validated in two locations, namely at S3 (Dabosingkep) and S4 (Muntok), as seen in Fig. 8. The surface elevation data at S3 and S4 are obtained from the Indonesian navy database. The data are for the 1-hour free surface elevation. The model and its validation consider the period of November 2013, as seen in Figs. 5a and 5b, respectively. Using Eq. (4), the errors are 3.94 and $4.95 \%$, which are adequate for validation.

The surface elevation validation of the local model is performed at S1 (tidal field measurement) as shown in Fig. 10. The numerical model result values are validated using 10-minute-interval surface data. The validation result is $7.13 \%$ error, which is considered to be a good validation, as illustrated in Fig. 5c. 

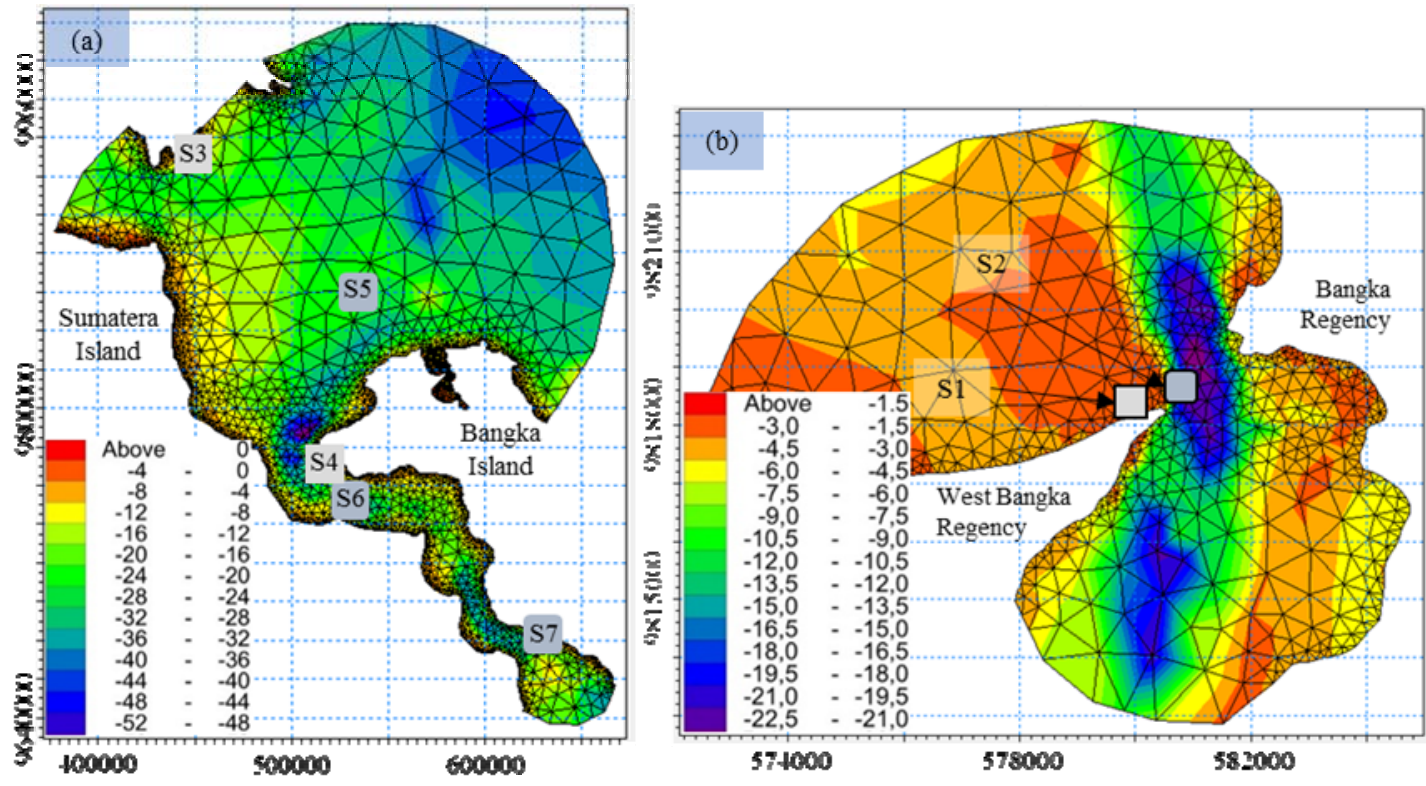

Fig. 4. Mesh of (a) global model and (b) local model
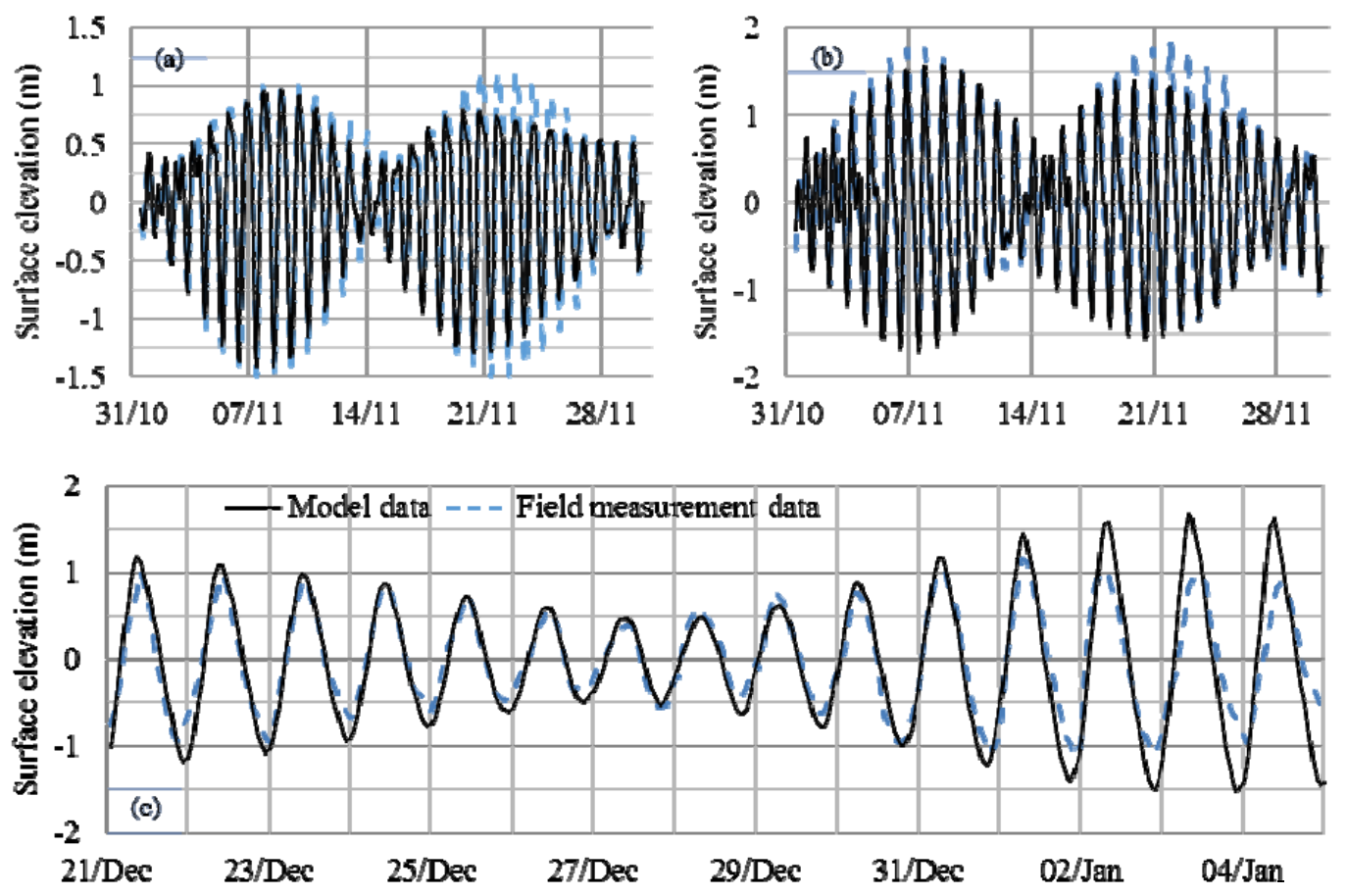

Fig. 5. Surface elevation validation result (Dabosingkep Station, Muntok Station, and field measurement data are shown in (a), (b), and (c) respectively)

2) Tidal Current Validation: The validation of the tidal current model for the global model is carried out at locations S5, S6, and S7, as seen in Fig. 4a. The data are also obtained from the current velocity database from the Indonesian navy. The locations of the three validation points are Tujuh Island (S5), Amelia Shoal (S6), and Nemesis Shoal (S7). The data resulting from the model of the uppermost layer are compared with these Indonesian navy data. The error calculation using Eq. (4) gives values of 7.98, 7.27, and 8.57\% for the three stations, respectively. Figs. 6a, 6b, and 6c show the validation results, which present a good agreement.

The validation of the local model of tidal current is carried out using field measurement data at location S2 (see Fig. 4b). The data are available in 10-minute intervals as well as in the 10-layer composition, which gives a detailed validation. Fig. 13 shows the validation. Table I shows the validation summary for each layer and the average error is $11.4 \%$. From the table it can be seen that the result for layer 7 gives the smallest error. As it is relatively far from the sea bed and ocean surface, the effects of both bed resistance and free surface waves do 
not interfere with the physical current generation. Layers 1, 2, 9, and 10 give large errors since they are close to the upper and bottom boundaries.

TABLE I. Errors of tidal current validation at every layers

\begin{tabular}{|c|c|c|c|c|c|c|c|c|c|c|}
\hline Layers & $\mathbf{1}$ & $\mathbf{2}$ & $\mathbf{3}$ & $\mathbf{4}$ & $\mathbf{5}$ & $\mathbf{6}$ & $\mathbf{7}$ & $\mathbf{8}$ & $\mathbf{9}$ & $\mathbf{1 0}$ \\
\hline Errors (\%) & 11 & 11 & 10.5 & 10.7 & 10.7 & 10.8 & 10 & 10.2 & 11 & 17 \\
\hline Average (\%) & \multicolumn{8}{|c|}{11.4} \\
\hline
\end{tabular}
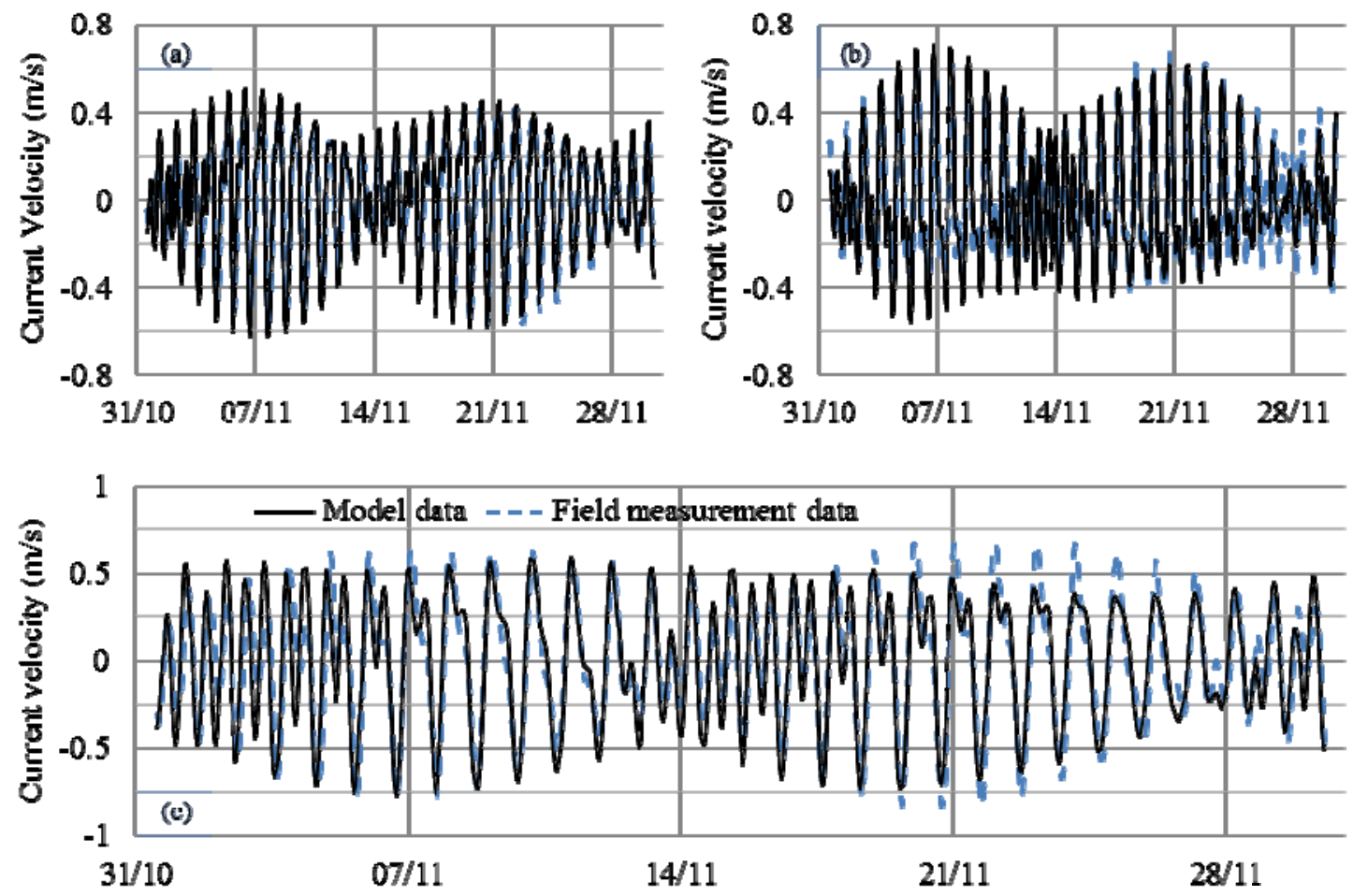

Fig. 6. Results of validation of global model of tidal current velocity (Tujuh Island, Amelia Shoal, and Nemesis Shoal are shown in (a), (b), and (c) respectively)
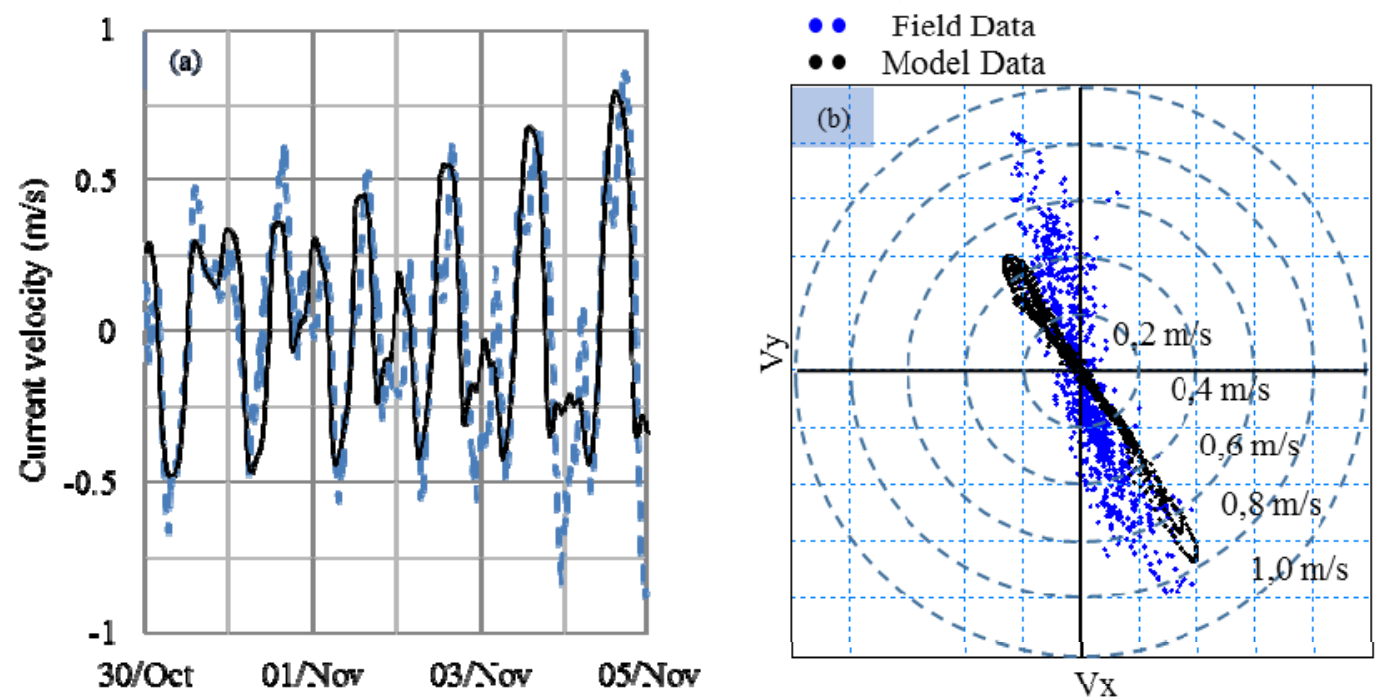

Fig. 7. The resulting (a) time series and (b) scatter plot diagrams of the validation of the local model of tidal current velocity 


\section{A. Analysis of Tidal Current Model}

Analysis of the tidal current model is performed to select the potential site for energy harvesting. The analysis is carried out using the local model. It consists of observations using the resulting spatial distribution of velocity under various tidal conditions (see Fig. 8), scatter plots of the model results at six points in the area of interest (i.e. points 1 to 6, as seen in Fig. 9), and velocity cross-sections of three sections, A-A, B-B, and C-C (see Fig. 9). The presented analysis is intended to give an overview of velocity in the local model. Further, the target output is a base for determining the selection of the potential site.

The spatial distribution of velocity is presented in Fig. 8. The potential velocity is obtained in the spring flood condition, in which the highest velocity reaches $1.1 \mathrm{~m} / \mathrm{s}$. At the narrowest part of Kelabat Bay, we can see the potential velocity not only during the spring flood condition but also during the spring ebb and neap ebb conditions. During the neap flood condition, however, the velocity change is not significant.

The analysis using current scatter plots refers to Fig. 9. Observations are made at six points of interest in the outer, narrowest, and inner parts of the bay. The scatter plots of the model results can be seen in Fig. 10. The velocity scatter plots at points 5 and 6 do not show a high velocity magnitude, as illustrated in Figs. 10c and 10d. In contrast, the other four points, which are located in the middle of the bay, show higher magnitudes of tidal current velocity. In particular, point 1 in Fig. 10a and point 2 in Fig. 10b present the most promising sites among those studied, with a maximum velocity of $1.2 \mathrm{~m} / \mathrm{s}$. These potential sites are considered.

Referring to Fig. 9, which shows the velocity magnitude cross-sections of three sections, namely A-A, B-B, and $\mathrm{C}-\mathrm{C}$, it can be seen that the higher velocities are found more or less in the middle part of the bay at the narrowest area (cross-section B-B). The velocity in the cross-section B-B is 0.9 m/s, as presented in Fig. $11 \mathrm{~b}$.

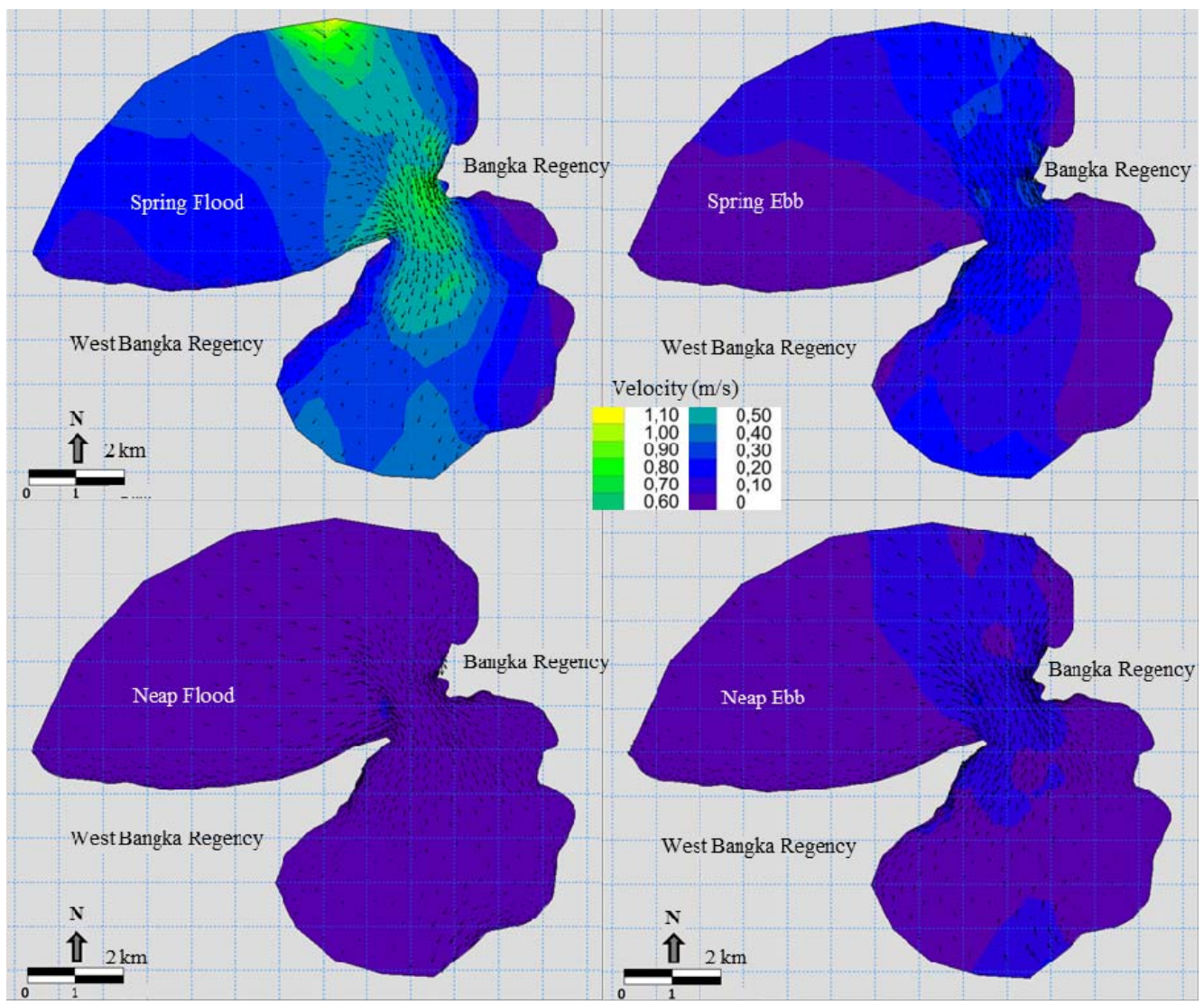

Fig. 8. Spatial distribution of tidal current velocity under various conditions 


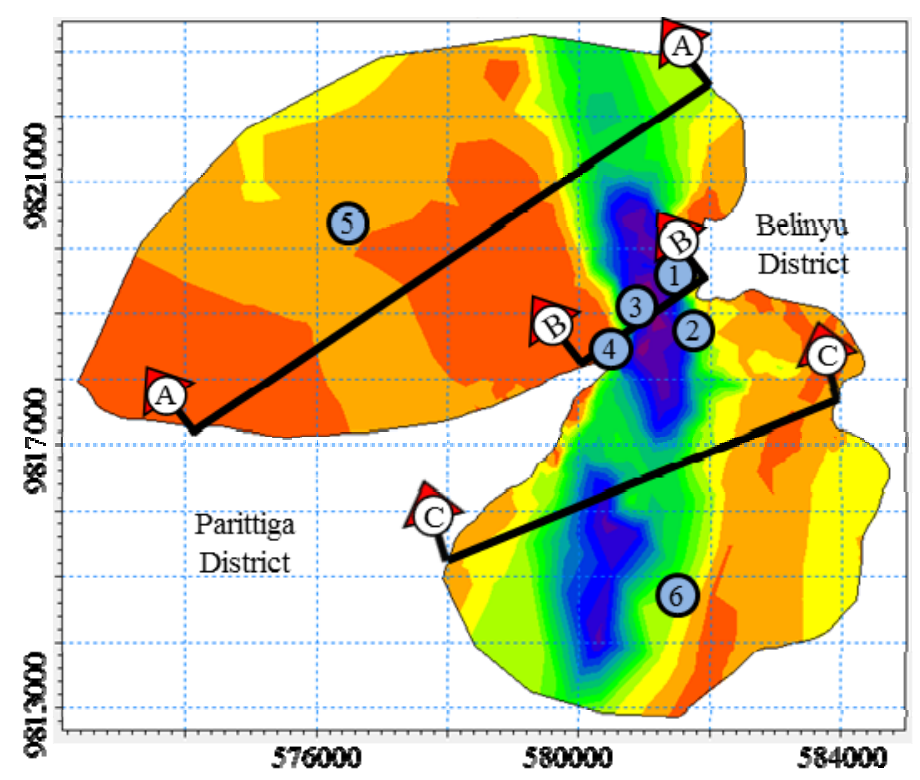

Fig. 9. Location of the interest points and cross-sections
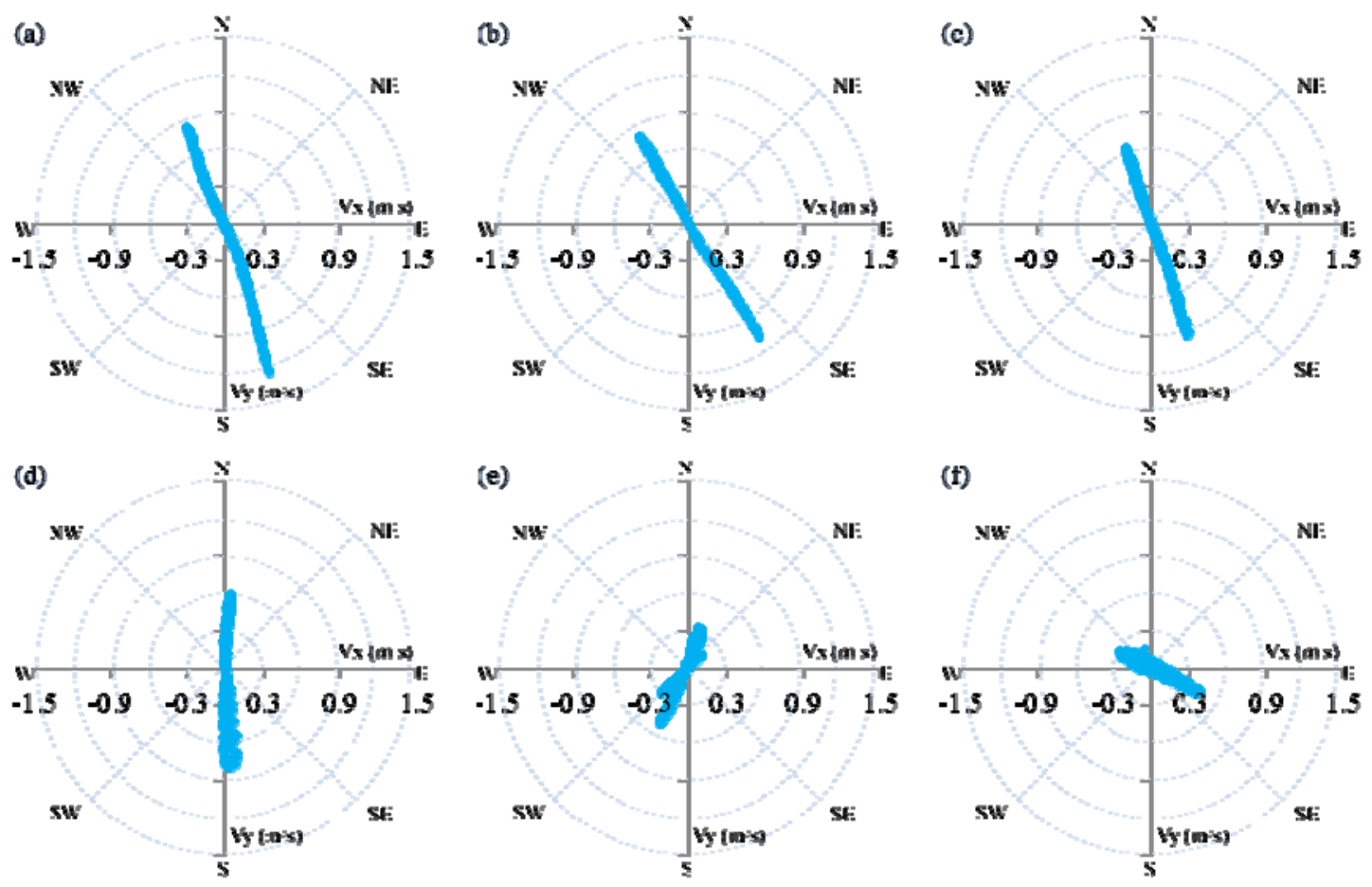

Fig. 10. The resulting scatter plots for each point of interest (points 1 to 6 are presented in diagrams (a) to (f), respectively) 

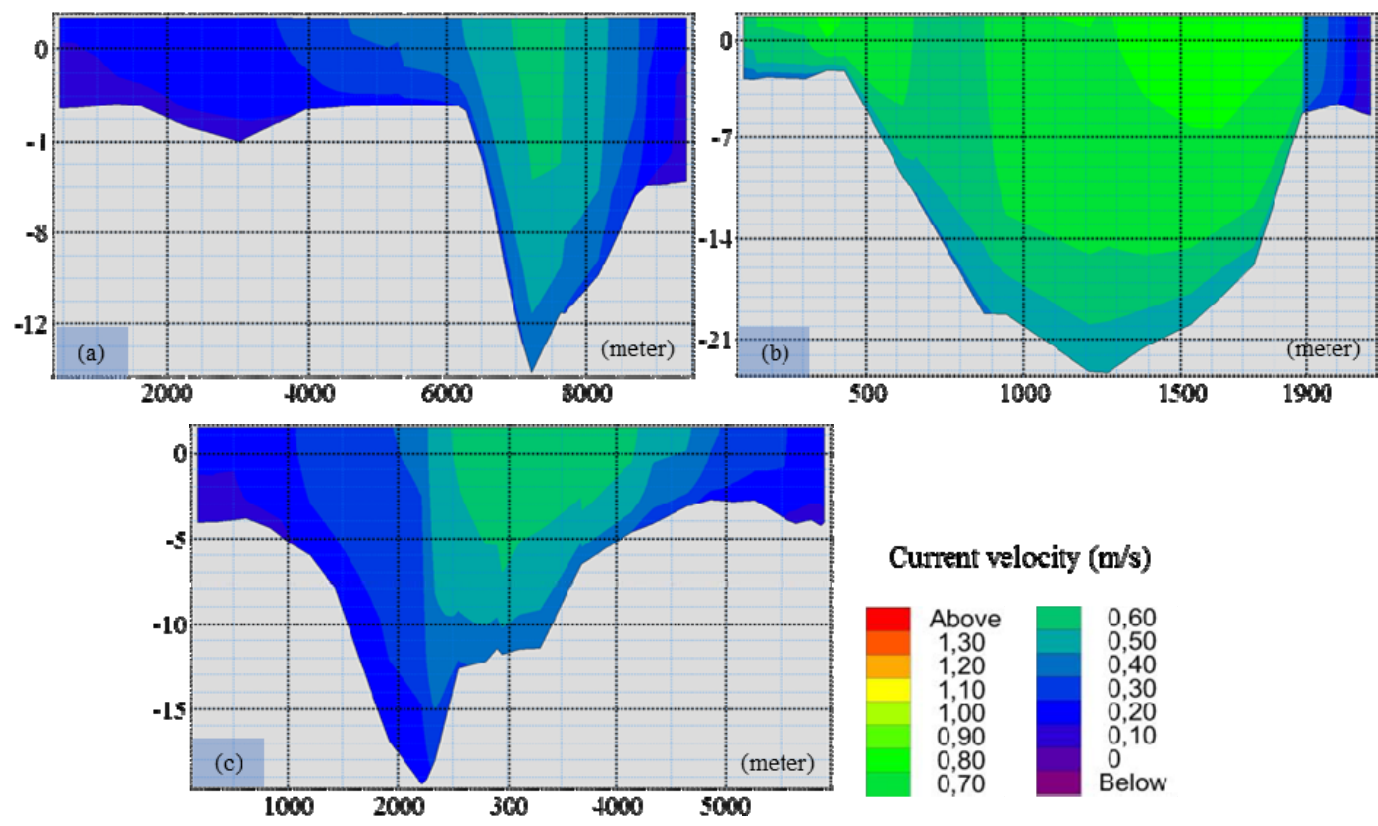

Fig. 11. Distribution of cross-section velocity under spring flood condition (A-A, B-B, and C-C are given in (a), (b), and (c))

\section{B. Power Extraction Analysis}

The energy power calculation is conducted at the five potential sites, which are located in the narrowest part of the strait and are called Kelabat 1 to 5, respectively, as seen in Fig. 12a. The depth and tidal current velocity characteristic of the Kelabat potential sites listed in Table II are used as the criteria for the turbine selection. The depth-averaged tidal current velocity is $0.347 \mathrm{~m} / \mathrm{s}$ and the average depth is $9.8 \mathrm{~m}$. A Gorlov helical turbine is selected.
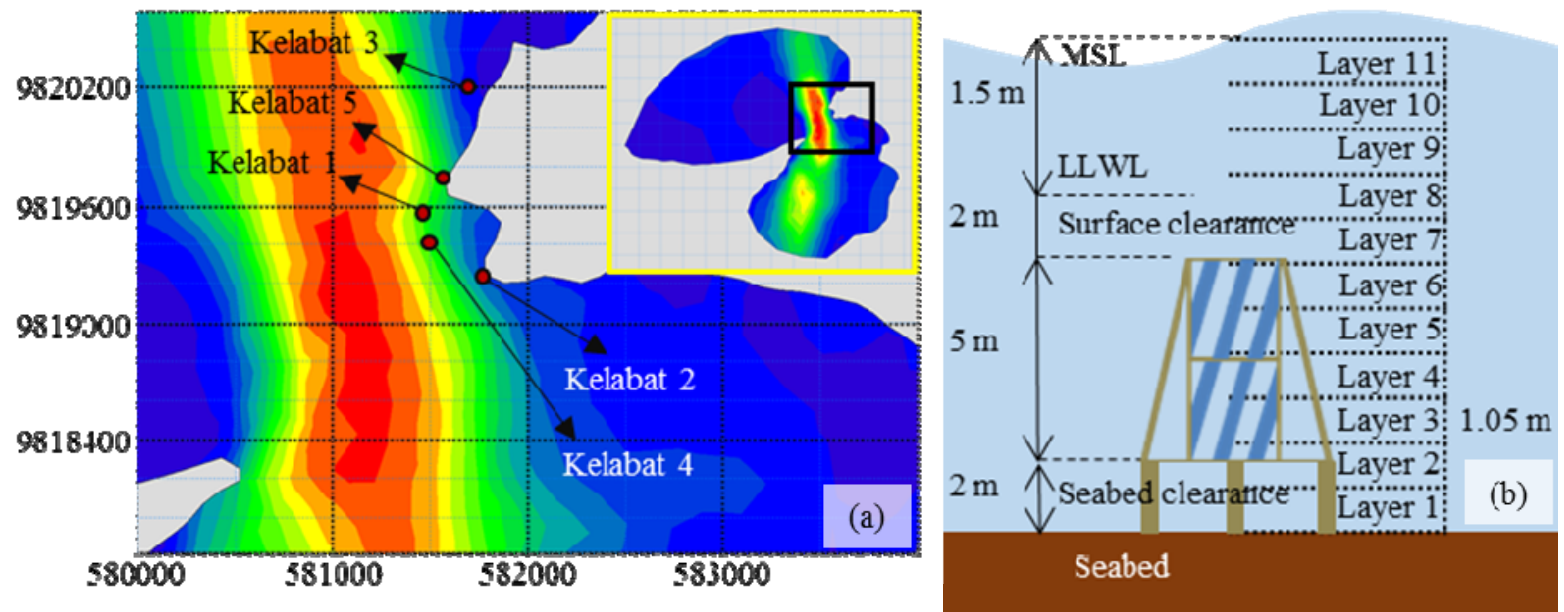

Fig. 12. (a) Locations of potential sites; (b) illustration of device operation at Kelabat

The cut-in speed of The Gorlov Helical Turbine is $0.5 \mathrm{~m} / \mathrm{s}$, which is relatively low with good efficiency. Other turbine characteristics are given in Table III. The device is mounted on the seabed at a height of $5 \mathrm{~m}$. It contains two turbines in one device and allows a minimum clearance of $2.3 \mathrm{~m}$ from the Lowest Low-Water Level (LLWL) to ensure the safety of boat navigation and other water activities by local people at Kelabat 2, 4, and 5. However, at Kelabat 1, only one turbine per device could be utilized. Moreover, Kelabat 2, which had a depth of only $3.6 \mathrm{~m}$, was not suitable for any instrument. The LLWL is located at $2.3 \mathrm{~m}$ below MSL at all sites. The position of the device is illustrated in Fig. 12b.

Fig. 13 shows the one-year tidal current output resulting from the numerical model of layer 4 at Kelabat 1 . The figure also shows an example of the magnitude of the extracted current velocities that can move the turbine, which are the data values that are above a threshold line. The threshold line is the turbine cut-in speed. 
TABLE II. Parameters of the potential sites

\begin{tabular}{|c|c|c|c|c|c|c|}
\hline Sites & $\begin{array}{c}\text { Depths } \\
\mathbf{( m )}\end{array}$ & $\begin{array}{c}\text { Average } \\
\text { velocities (m/s) }\end{array}$ & $\begin{array}{c}\text { Maximum } \\
\text { velocities (m/s) }\end{array}$ & $\begin{array}{c}\text { Layers } \\
\text { covered }\end{array}$ & $\begin{array}{c}\text { Number of } \\
\text { turbines }\end{array}$ & $\begin{array}{c}\text { Total power } \\
\mathbf{( k W h )}\end{array}$ \\
\hline Kelabat 1 & 8.4 & 0.373 & 1.24 & $3-8$ & 1 & 329.71 \\
\hline Kelabat 2 & 10.5 & 0.368 & 1.08 & $1-9$ & 2 & 399.98 \\
\hline Kelabat 3 & 3.6 & 0.347 & 0.92 & Not suitable & - & - \\
\hline Kelabat 4 & 12.6 & 0.345 & 1.14 & $2-7$ & 2 & 438.98 \\
\hline Kelabat 5 & 13.8 & 0.304 & 1.08 & $2-7$ & 2 & 328.64 \\
\hline
\end{tabular}

TABLE III. Specifications of The Gorlov Helical Turbine

\begin{tabular}{|c|c|c|c|c|c|}
\hline Parameters & Swept area & Height & Foundation & Efficiency & Cut-in speed \\
\hline Value (per turbine) & $2.5 \mathrm{~m}^{2}$ & $2.5 \mathrm{~m}$ & Floating structure & $31.5 \%$ & $0.5 \mathrm{~m} / \mathrm{s}$ \\
\hline
\end{tabular}

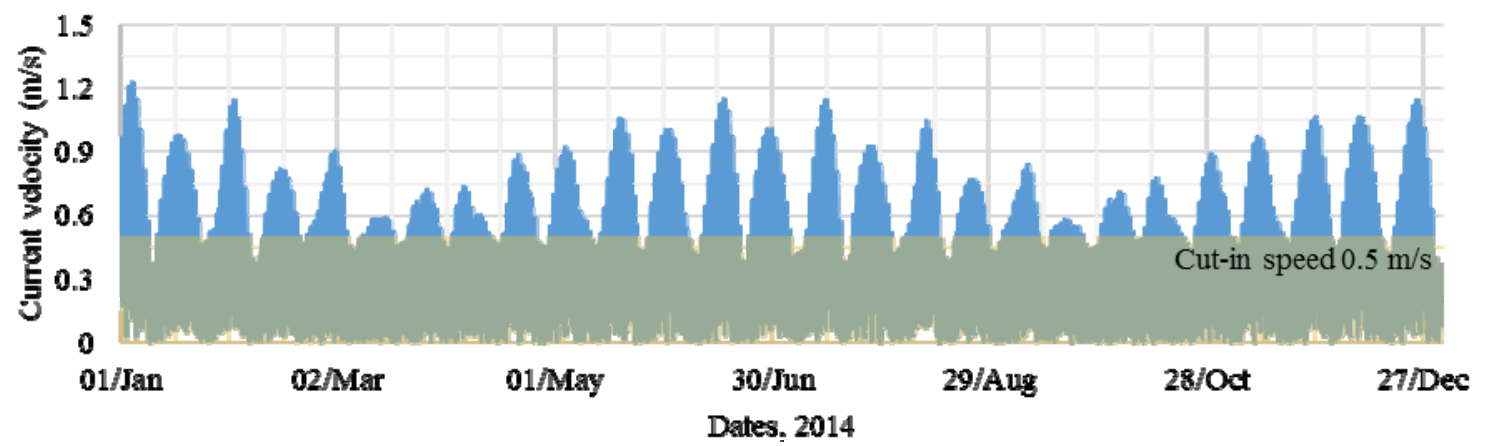

Fig. 13. The resulted threshold of cut-in speed according to current velocity at Kelabat 1 in layer 4

Power calculation is carried out using Eqs. (5) and (6), where $E$ is the extracted power, $\rho$ is the fluid density $\left(1025 \mathrm{~kg} / \mathrm{m}^{3}\right), \eta$ is the system efficiency, $A$ is the turbine swept area, $v$ is the tidal current velocity, and $E_{i}$ is the power for the i-th layer. The area covered needs to be considered thoroughly, since the layers change dynamically with fluctuation of the water level. The considered layers are layers that are covered by the turbine area, as given in Table III. The total power is the sum of the power in the turbine-covered layers, as illustrated in Eq. (6). The power calculation is conducted for 365 days in 2014. The obtained extracted powers are presented in Table III.

$$
\begin{aligned}
& E=\frac{1}{2} \times \rho \times \eta \times A \times v^{3} \\
& E=E_{1}+E_{2}+\ldots+E_{i}
\end{aligned}
$$

\section{VI.CONCLUSION}

The numerical model of Kelabat Bay presents good agreement with the primary and secondary validation data in both the surface elevation validation and the tidal current velocity validation. Further model analysis of the tidal current indicates that P1 is a potential location; it contains five trial sites, namely Kelabat 1 to 5. Kelabat 3 generates more power than the other sites using The Gorlov helical turbine.

Further research considering turbines with lower cut-in speeds is needed in order to harvest a smaller current velocity. However, we have discovered a potential site that has continuous availability of current, thus offering hope of future energy harvesting around Bangka Island.

\section{ACKNOWLEDGMENT}

The authors would like to thank the Ministry of Marine Affairs and Fisheries of the Republic of Indonesia for funding this research. 


\section{REFERENCES}

[1] Sugiyono A et al., Indonesia Energy Outlook 2016: Energy Development in Supporting Green Industry, Indonesia: Agency for The Assessment and Application of Technology, 2016.

[2] Rahman A, Venugopal V, "Parametric analysis of three dimensional flow models applied to tidal energy sites in Scotland," Estuarine, Coastal, and Shelf Science, Vol. 189, 2017, pp. 17-32.

[3] Jeyaraj SK, Venugopal V, "Assessment of tidal energy potential along The Gulf of Khambhat, Gujarat, India," Conf. Offshore Renewable Energy (CORE 2016).

[4] Novo PG, Kyozuka Y, "Field measurement and numerical study of tidal current turbulence intensity in the Kobe Strait of the Goto Islands, Nagasaki Prefecture,” Journal of Marine Science and Technology, Vol. 22, 2016, pp. 335-360.

[5] Karsten RH et al., "Assessment of tidal current energy in the Minas Passage, Bay of Fundy,” Journal of Power and Energy, Vol. 222, 2008.

[6] Gao P et al, "Potential assessment of tidal stream energy around Hulu Island, China,” Procedia Engineering, Vol. 116, 2015, pp. 871879.

[7] Suryawati SH et al, "Kajian sosial ekonomi pengembangan dan pemanfaatan energi baru dan terbarukan di sektor kelautan dan perikanan,” Research final report, Balai Besar Penelitian Sosial Ekonomi Kelautan dan Perikanan, 2013.

[8] Sachoemar SI, Kristijono A, "Evaluasi kondisi lingkungan perairan estuaria Teluk Kelabat, Bangka pada musim timur,” Jurnal Teknik Lingkungan P3TL-BPPT, Vol. 6, 2005, pp. 438-445.

[9] Takagi H et al., "Projection of coastal floods in 2050 Jakarta," Urban Climate, Vol. 17, 2016, pp. 135-145.

[10] Takagi H et al., "Flow intensification induced by tidal oscillations in tributaries of the Mekong River," International Journal of Safety and Security Engineering, Vol. 6, 2016, pp. 697-703.

[11] Jia P et al, "Simulation of the effect of an oil refining project on the water environment using the MIKE 21 model," Physics and Chemistry of the Earth, Vol. xxx, 2017, pp. 1-10.

[12] Work PA et al., “Tidal stream energy site assessment via three-dimensional model and measurements,” Applied Energy, Vol. 102, 2013, pp. 510-519.

[13] Murray RO, Gallego A, “A modelling study of the tidal stream resource of the Pentland Firth, Scotland,” Renewable Energy, Vol. 102, 2017, pp. 326-340.

[14] DHI Software, MIKE 21 \& MIKE 3 Flow Model FM, Denmark: DHI Water \& Environment, 2007, ch. 2.

[15] Roger B et al., EPRI survey and characterization - Tidal in stream conversion devices, North America: Electric Power Research Institute, 2005, Appendix.S. M. Metev and V. P. Veiko, Laser Assisted Microtechnology, 2nd ed., R. M. Osgood, Jr., Ed. Berlin, Germany: Springer-Verlag, 1998.

\section{AUTHOR PROFILE}

H. Ajiwibowo's research interests are in physical and numerical modeling of water resources and ocean engineering. He graduated from Civil Engineering Department, Bandung Institute of Technology in 1988 and Graduate Program in the same field at Oregon State University (OSU), Corvallis, Oregon, USA. He graduated from OSU in 2002. He is currently an Associate Professor at the Faculty of Civil and Environmental Engineering, Bandung Institute of Technology, Indonesia.

M.B. Pratama's research interest is in hydrodynamic numerical modeling. He graduated from Bandung Institute of Technology in 2016 and is currently a Research Assistant for the Ocean Engineering Program, Bandung Institute of Technology, Indonesia.

A. Wurjanto's research interests are of meteorology ocean analysis and hydrodynamic numerical modeling. He graduated from Civil Engineering Department, Bandung Institute of Technology in 1983 and Graduate Program in the same field at University of Delaware at Newark, Delaware, USA at 1997. He is currently an Associate Professor at Faculty of Civil and Environmental Engineering, Bandung Institute of Technology, Indonesia. 